\title{
More Seeing-in: Surface Seeing, Design Seeing, and Meaning Seeing in Pictures
}

\author{
Peer F. Bundgaard
}

\begin{abstract}
The paper considers the phenomenology of aesthetic experience as "twofold" in a sense akin to Wollheim's (Painting as an art. Princeton University Press, Princeton, 1987). However, as regards the perception of artworks proper, the notion of twofoldness needs further specification. In the wake of Wollheim, the philosophy of pictorial representation has addressed the second, 'configurational' aspect of twofoldness in rather vague terms without addressing the aesthetic or pictorial function of this correlate of aesthetic perception. I shall talk about such coawareness as "design-seeing" and assign two decisive properties to pictorial design. First, I will point to a depicting property of design that is a distinctive property of pictures. Design in pictures is such that it can depict two (or, in rare cases, even more) fully consistent objects without the picture becoming ambiguous. Next, I'll show that the design structure of a painting is not simply a structure in virtue of which something is represented to the eye, but also in virtue of which meaning is conveyed to the eye. If I am right in considering the design level of pictures as a genuine platform for meaning making, then seeing-in doubled with design seeing occurs every time lines and shapes do not only depict, but also mean something
\end{abstract}

Keywords Seeing-in $\bullet$ Surface seeing • Design seeing • Twofoldness • Pictorial meaning

\section{Preamble}

Do pictorial works of art have inherent properties that inform our experience of them, i.e. qualify this experience to make it "aesthetic?" By "aesthetic," I do not mean pleasant, rewarding, or accompanied by an appreciative judgment of something that is considered beautiful or valuable in some respects. I simply understand it to mean the experience of a kind of object that differs from other

P.F. Bundgaard $(\bowtie)$

Center for Semiotics, Aarhus University, Aarhus, Denmark

e-mail: sempb@dac.au.dk 
objects in that its creator has intended it to be a work of art and designed it accordingly. And by "inform," I mean that such properties elicit this kind of experience and shape its phenomenology, causing it to be of a certain sort.

While I do think such properties exist and trigger aesthetic experience, I also consider it vain to establish a list of such essentially aesthetic properties that qualify a given object as a work of art. For two reasons: first, because a work of art need not display all of them; second, because very few, if any, can be found exclusively in pictorial works of art. Nevertheless, in this chapter I will point at two prototypical and essential properties of art that do inform people's experience of them.

The first is that they are stratified objects insofar as they simultaneously represent something and present the design in virtue of which they depict that thing. This makes the phenomenology of aesthetic perception "twofold," as Richard Wollheim (1987) famously put it: the visual experience of paintings consists of the recognition of an object represented on a surface (what he calls "seeing-in") accompanied by the awareness of that surface. This claim is far from evident with regard to picture seeing (it may not be twofold at all) and the exact nature of "surface seeing" (which ultimately is correlated to precisely what we or Wollheim mean by "surface"). The first section of this chapter is an investigation into what actually characterizes the "twofoldness" of aesthetic perception. To this effect, I shall propose a distinction that seems to have escaped Wollheim and most of his commentators: twofoldness is not simply simultaneous awareness of both the represented (or otherwise appearing) object and the matter (the canvas, the cloud, the frosty pane, and so on) in which it is represented or in which it appears. If this were the case, seeing faces in clouds and seeing them in canvases would be tokens of the same kind of experience. Twofoldness in the aesthetic domain concerns rather the simultaneous awareness of the represented object (the motif) and the surface, which (unlike clouds, walls, and frosty panes) has been designed to depict that object; that is, to enable a certain kind of visual experience. The distinction between material support (canvas) and depicting surface leads me to pinpoint an essential, close to unique property of paintings (including, as we shall see, artful photographs): they may have multiply depicting surfaces, that is, surfaces which enable two or more equally consistent visual experiences, without being bi-stable.

The next property I will focus attention on in the last section of this chapter is that paintings are platforms for meaning-making in ways that plain pictures are not. This is so not only because of what they represent (which may appear as culturally, religiously, historically, or biologically significant), but also, and first and foremost, by virtue of their depicting surface, i.e. by virtue of the way in which the depicting surface has been designed to produce certain meaning effects. There is a top-down constraint in seeing an object in a picture that does not exist when the same kind of object is seen face to face. I only see a given object in a picture because someone wanted to express himself by means of that object, and ultimately because he intended to present that object in that picture the way he did. In virtue of this intentional setting, picture seeing at large is obviously not simply about recognizing objects; it also, and importantly, means exploration. In virtue of this intentional condition, as it were, an important task for the philosophy, the psychology, and, 
of course, the semiotics of art therefore consists in laying down those techniques and tools by means of which artists in general shape their meaning intentions, and in showing how these tools and techniques can take on various specific semiotic functions in different works of art. ${ }^{1}$ As regards the phenomenology of aesthetic experience, and twofoldness, this has a major consequence: our perception of works of art is always twofold, even when the depicting surface does not display any obtrusive design properties, i.e. even when the style is perfectly naturalistic or neutral. In such cases it remains an inherent part of aesthetic perception, not because of its visual saliency, but because of its semiotic saliency: it expresses a meaning intention; it is the platform for the construction of meaning effects.

\section{The Strata of Artwork and Their Perceptual Correlates}

According to Husserl (1980), paintings are three-layered objects and each layer can be attended to as such; i.e. each layer can be the objective correlate of a perceptual act. (1) Paintings are plain material things endowed with surfaces on which colored marks of pigment or other materials can be observed. (2) They depict objects, enabling a certain visual experience. (3) They are pictorial objects with a certain content, a motif. ${ }^{2}$ In this chapter, I will only discuss the first two aspects of paintings and the modes of perception through which we attend to them. I will do so along the lines suggested by Dominic Lopes in his investigation into the nature of picture seeing (Lopes 2005), with the ultimate goal of both refining the understanding of twofoldness in aesthetic perception and enriching the concept of depicting surface.

\subsection{Surface and Surface Seeing}

When it is regarded as a thing, a picture is an object with a surface covered with marks made of a certain matter and with certain qualitative properties. Essential to this global and straightforward characteristic of artwork is, as Lopes (2005) notes, that the surface and its marks are here considered independently of the visual experience they give rise to, what they depict, and their depicting function in general. Surface seeing, that is to say the phenomenological or perceptual correlate of the surface, is "a visual experience of a picture as a configuration of marks, colors,

\footnotetext{
${ }^{1}$ Cf. Hyman 2003, 2006, and the present volume for a view akin to what I propose here.

${ }^{2}$ Husserl states it the following way: "We have three objects: (1) the physical picture, the thing made out of canvas, marble, etc.; (2) the representing or depicting object; and (3) the represented or depicted object" (Husserl 1980, p. 19).
} 
and textures on a two-dimensional surface" (Lopes 2005, p. 36). Thus, I may look at a picture and see cracks in the pigment or, as Lopes again remarks, notice that the canvas is old; I may be able to see a fine layer of dust covering it. I can approach it and perhaps see blotches of color or reflections and shades due to ambient light; or finally I can consider it as being oriented in this or that way (because it is oriented in this or that way relative to me). Now, all these elements - the quality of the pigment, the age of the canvas, the orientation of the surface, dust, and lighting conditions - may be very real parts of the aesthetic experience, but they are not genuine features of it, since none of them concern the artwork as a depicting object, endowed with a design in virtue of which something is represented to a viewer. Thus, surface seeing proper-i.e. awareness of the painting in its materialityblocks picture seeing proper. As Lopes states: "not all visible properties of a picture surface are ones in virtue of which it depicts a scene" (Lopes 2005, pp. 35-36). It is also worth noting in passing that surface properties are not only and not strictly material properties of a painting; they are also correlates to perceptual intentionality (i.e. a specific manner of attending to the object). For instance, a conservator may be concerned by the physical state of a part of a picture and then take one step back and appreciate what that very part depicts and the way it does it. In the former case, he is attending to the canvas and its physical properties; in the latter case, he is attending to the depicting surface and the motif that the surface enables us to experience. This leads us to those properties which depict something and thus elicit what Wollheim called the experience of seeing-in: the experience of recognizing or seeing something represented in a picture.

\subsection{Design and Design Seeing}

According to Husserl, the second ontological layer of a picture (the Bildobjekt) is the picture qua depicting surface, i.e. an object endowed with a surface that has been designed to make certain represented objects appear in a certain way. The perceptual correlate to this stratum is well characterized by what Lopes (2005) calls "design perception." The design of a picture is a considerable subset of its surface properties. It is "a configuration, on a two-dimensional surface, of marks, colors, and textures in virtue of which the surface depicts a scene" (Lopes 2005, p. 28). Hence, design seeing is, correlatively, a visual experience of such a configuration of marks which have a genuine depicting function and as such — at least following this first definition - are genuine features of aesthetic perception. However, since the design is not the same as the content or the motif of the picture, design seeing proper "comprises the surface configurations that you see when you see the picture surface without seeing anything in it and that are responsible for your seeing something in it" (Lopes 2005, p. 25). In other words, what Lopes calls design seeing is not the trivial fact that when you see a picture, say the Mona Lisa, you see what you see in it in virtue of the pictorial design used by the painter to enable a certain kind of visual experience. If that were the case, there would be no conscious experience 
of the design; it is not part of the phenomenology of the experience. Design seeing proper is thus seeing the design as design independently of what it actually depicts. ${ }^{3}$

Design seeing is perceptual awareness of the purely pictorial properties of the object, e.g. the characteristics of the contours (clear-cut, fuzzy, chiaroscuro, etc.), the chromatic properties, luminance, the degree of representational realism, perspective (simple, multiple, ambiguous), point of view (generic, non-generic), and so on and so forth up to our simple categorization of a picture as, say, a "Fontana," a "Millet," a "Pollock," or, on an even larger scale, "Cubist," "Post-Impressionist," independently of what the picture represents. To this extent, and by contrast with surface properties, design properties are genuine correlates of aesthetic perception: you do not just see the represented objects, you also see the way in which they are given, their manner of presence.

However, and as just mentioned, it is important to stress that considering design properties as genuine features of aesthetic perception or picture seeing does not explain how or to what extent design is a genuine part of aesthetic perception. There is indeed a difference between, on the one hand, asserting the truism that design informs aesthetic perception because it is thanks to the design that we see something in the painting, and, on the other, making the claim that we are genuinely co-aware of the design when we see an object in a picture, that is to say that our act of seeing the motif of the picture (the picture as Bildsujet) is fused with our perception of the design of the picture as a depicting surface (the picture as Bildobjekt). In the former case, seeing what is in the picture implies "seeing (in virtue of) design," but only in the latter case is the act of seeing what is in the picture accompanied by or doubled with design seeing proper. ${ }^{4}$ As we shall see, it seems perfectly sensible to claim not only that we "see (in virtue of) design," but also that we can consciously focus our attention on pictorial design as design, without claiming that design perception is a genuine part of aesthetic perception or fused with seeing the motif.

In Sects. 2.3, 2.4 and 2.5, I will consider this issue in more detail with a view to clarifying Wollheim's notion of "twofoldness" and proposing a refined description of the depicting surface.

\subsection{Seeing-in and Design, Seeing-in and Surface}

Naturally, the role one assigns to surface seeing and design seeing in aesthetic perception has an effect on what one considers the phenomenology of such perception to be. Let us first take a look at the definitions of design and design

\footnotetext{
${ }^{3}$ Lopes puts it like this: "It is only in virtue of seeing the configuration of marks on its surface, and being sensitive to visible changes in them, that we see anything at all in the picture. However, seeing a pictorial design face to face does entail seeing the design as a design-it does not entail design-seeing" (Lopes 2005, p. 28).

${ }^{4}$ The distinction between "seeing design" and "design seeing" is developed by Nanay (2010).
} 
seeing. Following Lopes's definition, to perceive design as design is to perceive it independently of what it depicts. One could then take a Gombrichian stance and assert that design perception is not a feature of aesthetic perception proper if we understand this to be the experience of the depicted object as the object seen face to face. So you are either immersed in seeing Dora Maar in Picasso's picture or you consider what design features enable this visual experience. You cannot have both at the same time. Gombrich says it like this:

A master of introspection, Kenneth Clark, has recently described [...] how even he was defeated when he attempted to 'stalk' an illusion. Looking at a great Velázquez, he wanted to observe what went on when the brush-strokes and dabs of pigment on the canvas transformed themselves into visions of transfigured reality as he stepped back. But try as he might, stepping forward or backward, he could never hold both visions at the same time, and therefore, the answer to his problem of how it was done always seemed to elude him.

(Gombrich 1960, p. 5; also quoted in Lopes 2005, p. 38)

Gombrich would clearly not subscribe to the strong interpretation of design seeing as a genuine, full-blown feature of aesthetic perception. Either you have design and surface perception or you have the immersed experience of the motif; just as you, in the famous drawing, have either duck or rabbit, but never both simultaneously (Gombrich 1960, p. 4).

Nevertheless, the definition also lends itself to the opposite, Wollheimian interpretation: since design is what makes us see whatever we see in a picture, design is immediately displayed in the picture. We see the object in the design in virtue of the physical marks on the physical surface. The phenomenology of aesthetic perception is thus, in essence, "twofold." It is characterized by the double, fused, simultaneous awareness of the objects we see in the picture and the surface on which, in which, through which or in virtue of which we see them. ${ }^{5}$ This perceptual recognition of objects in surfaces is what Wollheim calls seeing-in. The correlate to "recognitional" seeing-in is awareness of the surface in which the object appears as well as of the "configurational" properties of the marks upon it (the quoted terms are borrowed from Wollheim). The conflated character of these aspects is what characterizes the visual experience of a depicting object.

Seeing-in is a distinct kind of perception, and it is triggered off by the presence within the field of vision of a differentiated surface. [...] When the surface is right, then an experience with a certain phenomenology will occur, and it is this phenomenology that is distinctive about seeing-in. [...] The distinctive phenomenological feature I call 'twofoldness', because, when seeing-in occurs, two things happen: I am visually aware of the surface I look at, and I discern something standing out in front of [ ...], something else. $[\ldots]$ The two things that happen when I look at, for instance, [a] stained wall [and see a figure of a boy in it] are, it must be stressed, two aspects of a single experience that I have, and the two aspects are distinguishable, but also inseparable. They are two aspects of a single experience, they are not two experiences. (Wollheim 1987, p. 46)

\footnotetext{
${ }^{5}$ I do not multiply the phrases for rhetorical reasons. As we shall see, it is not a straightforward affair to define the relation between surface/design and depicted object, both in general and according to Wollheim in particular.
} 
Fig. 1 Asger Jorn, Le canard inquiétant, 1959. (C) Donation Jorn, Silkeborg, billedkunst. $\mathrm{dk}$

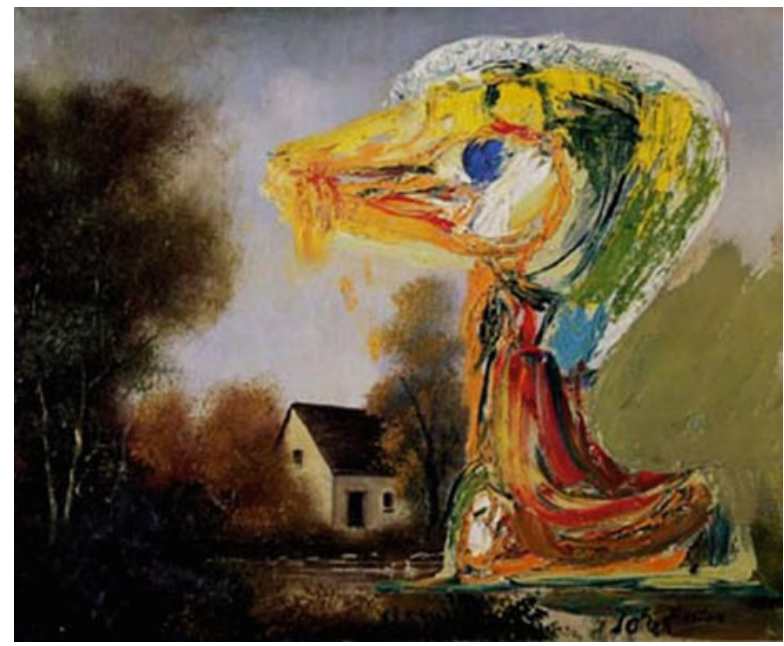

This is obviously the exact opposite of Gombrich's stance. To Wollheim, another duck, namely Asger Jorn's Ominous Duck, is likely to epitomize twofoldness (see Fig. 1).

In Jorn's Ominous Duck, both the structural design properties of the painting as a depicting surface (the evident fact that the duck has been painted on another painting) and the material properties of the duck itself (size, colors, brushstrokes) seem not only to be immediately picked up by perception, but also to be essential to understanding why the duck is ominous (and the painting humorous). Even though I do side with Wollheim in what we, for reasons of convenience, could call his debate with Gombrich, this is not the place to unravel all aspects of this discussion about the constituent elements of aesthetic perception. I only mention it here because the above quotations and the issues they address may indeed help us to better define what exactly twofoldness comprises, i.e. what the two aspects of the single aesthetic experience are, or rather what they are not. As will soon become clear, I do believe that the notion of twofoldness, also in Wollheim, remains unclear in one essential respect.

\subsection{Seeing Something in Walls and Seeing Something in Paintings}

So the question is how do surface (seeing) and design (seeing) combine with seeingin (Wollheim) or with the immersed experience of the motif (Gombrich)?

We have just seen that even though Gombrich accepted the analytical distinction between surface and design, to him this would still not have any import on the phenomenology of aesthetic perception. When you want to find out how a given 
artist has pulled off his stunt (say, succeeded in representing water lilies in a pond), you either get pigment on canvas (surface) or you get (sometimes incoherent) aggregates of shapes (design); that is, you either get the object (surface, design) or the motif. On the other hand, Wollheim's notion of twofoldness embraces exactly what Gombrich discards from aesthetic perception, and there is a good reason for this. This is what Wollheim says:

So, for instance, I follow the famous advice of Leonardo da Vinci to an aspirant painter and I look at a stained wall, or I let my eyes wander over a frosty pane of glass, and at one and the same time I am visually aware of the wall, or of the glass, and I recognize a naked boy, or dancers in mysterious gauze dresses, in front of [ ...] a darker ground. In virtue of this experience I can be said to see the boy in the wall, the dancers in the frosty glass. (Wollheim 1987, p. 46)

Naturally, this makes sense. You see a stained wall and in that wall you recognize the shape of something; your experience of seeing the figure is pervaded with your experience of seeing the wall. What examples like this show is that the very material support (wall, frosty pane, cloud) is an integrated feature of the phenomenology of that perception. But here is the key issue: what happens if we transpose this state of affairs to the perception of works of art, for instance the visual experience of some dancers painted by Degas? In these circumstances we get the wrong description. We are not seeing the dancers "in front of" the canvas (which is the immediate counterpart to "wall" and "frosty pane" in the quotation above); and our experience of seeing the dancers is not pervaded with our awareness of the canvas as canvas. If figures, for example, appear on a dark background, then it is dark because the wall and frosty panes appear dark; but upon perceiving a figure in a painting we would not say that the canvas is gray or yellow, we would rather say that the "floor" is gray or the "wall" is yellow. The reason for this is that seeing figures in walls and frosty panes is a two-stratum business; it consists of material surfaces and figures. Paintings, on the other hand, are three-strata affairs. They consist of material surfaces that have been intentionally transformed into depicting surfaces in virtue of which we see figures. Qualities in paintings specify the depicting surface, not the material support. ${ }^{6}$

In other words, the twofoldness Wollheim mentions cannot be exhaustively assimilated to the co-awareness of the physical support for depiction, the material surface. This becomes obvious just one paragraph further on in Wollheim's text, where he tells more or less the same story as Gombrich with his Clark anecdote:

The twofoldness of seeing-in does not, of course, preclude one aspect of the complex experience being emphasized at the expense of the other. In seeing a boy in a stained wall I may very well concentrate on the stains, and how they are formed, and the materials and colours they consist of, and how they encrust or obscure the original texture of the wall, and I might in consequence lose all but a shadowy awareness of the boy. [...] One aspect of the experience comes to the fore, the other recedes. And sometimes this

\footnotetext{
${ }^{6}$ This is also what Lopes notices with regard to the Clark anecdote in Gombrich: once you get too close to the canvas, you get the canvas qua pure surface without any design properties (Lopes 2005, p. 38).
} 
preference for one aspect of the experience gets carried to the point where the other aspect evaporates. Twofoldness is lost, and then seeing-in succumbs to an altogether different kind of experience. (Wollheim 1987, p. 47).

In Gombrich, there is no significant difference between the surface properties of a picture and its design relative to the aesthetic experience (you can look at the way Dora Maar's face has been designed or try to capture the exact hue of the pigment in virtue of which we see her lips, but in neither case can you perceive Dora Maar proper). Wollheim, in contrast, marshals some variant of this distinction, since, on the one hand, twofoldness requires awareness of the matter, the support in which the object is perceived; while he seems to follow Gombrich in saying that this awareness is not simply awareness of canvas, plain pigment, and so forth, because this would block seeing-in proper. In his twofold perception, the surface the viewer is supposed to integrate, along with the depicted object, is not simply the material support of the representation; it is rather the latter as it has been modified by the artist into a pictorial or depicting surface.

So here is the refinement of Wollheim's theory that I propose: seeing-in (i.e. the experience of seeing something in a painting) is doubled, not simply with awareness of the object in which we see it, but with the co-perception of the depicting, intentionally designed surface in virtue of which we see it. This distinctionbetween material support and depicting surface-has, to my knowledge, not been sufficiently brought to the fore, either by Wollheim himself or by his commentators.

\subsubsection{Seeing-in and Awareness of the Depicting Surface}

I shall return to what I mean by "awareness of object" compared to "co-perception of the depicting surface," but first I will give a simple example of what the latter may comprise.

Consider the Annunciation by Piero della Francesca (Fig. 2). As in some of his other paintings, the artist has chosen a non-generic vantage point ${ }^{7}$ from which the represented space appears in a somewhat collapsed perspective, making the spatial layout ambiguous and, for that reason, the depicting surface obtrusive. On the left side of the painting, Gabriel clearly appears to be at the same level as the figure of God painted on the wall in the background, whereas if you consider the lower part of the picture, he is just as clearly placed in the foreground, at the same level as Mary. ${ }^{8}$

\footnotetext{
${ }^{7} \mathrm{~A}$ vantage point is non-generic when a remarkable constellation of figures (or lines) can be achieved only from that point of view. There is, for example, only one highly unstable point of view from which the Necker cube appears as a 2D hexagon (see Petitot 2009a, b and Bundgaard 2009, 2011).

${ }^{8}$ This is, of course, an elegant and powerful way of giving a purely pictorial representation of the mediating function of angels and of the continuous transition from the divine to the earthly domain which is taking place at that moment.
} 
Fig. 2 Piero della Francesca, Annunciation, 1452-1458

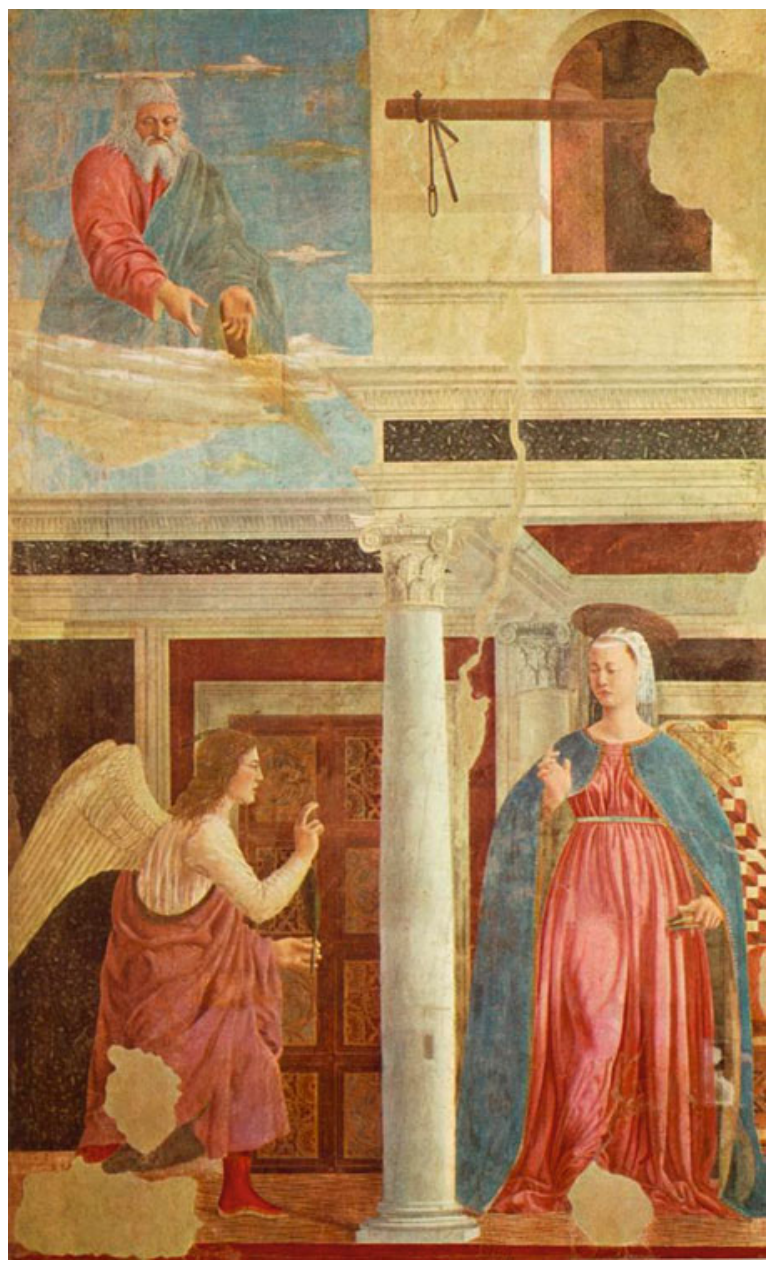

Now, the conspicuous presence of the depicting surface (because of its relative ambiguity) is of course not a property of the represented scene. Nor is it a property of the canvas. It is not the material properties of the canvas, say, its two-dimensionality and its "canvasness" as such, that pervade the visual experience of the scene. The obtrusive presence of the surface is rather the result of an artful exploitation of the canvas that yields a specific visual experience, both of the represented scene and of the presentational design through which the scene appears with its characteristic phenomenal properties.

In short, there is a difference between being aware of a pictorial surface such as Piero della Francesca's and being aware of the canvas as material support. The former is a genuine element of the aesthetic perception of the picture. It is a constitutive part of its phenomenology, whereas the latter is not. 


\subsection{Surface Perception and Design Perception}

In order to better capture the phenomenology of aesthetic perception proper (i.e. the perception of works of art independently of whether or not they are considered good), I will consider how the two kinds of perception identified by Lopes (surface or design perception) "double with" seeing-in, i.e. integrate the twofold character of such an experience. There are two issues to address here. (1) Even the most convinced Gombrichians would accept that nobody ever mistakes a picture for reality (and if they did, their experience would not be one of picture seeing, but a piece of illusory perception). So, from a Gombrichian perspective, picture seeing must also be doubled with something, namely awareness of the ontological nature of what one is looking at. What is this awareness and in what respect is this double character of picture seeing different from twofoldness in Wollheim's understanding? (2) Pictures come in different types; they are distributed on a continuum with, at one end, pictures with almost transparent design properties and, at the other end, pictures with obtrusive design properties, i.e. pictures where the viewer's conscious awareness of the design properties is an integrated feature of the phenomenology of that visual experience. How can the difference between the perceptions of these kinds of pictures be characterized?

Lopes (2005) addresses both these issues in one simple conceptual framework. To accommodate the diversity of picture types, he sets up a matrix with two sets of parameters. The first is whether seeing-in is illusionistic or non-illusionistic (where "illusionistic" means that seeing the object in the picture is indistinguishable from seeing it face to face ${ }^{9}$ ), and the second is whether seeing-in is doubled with or divided from design seeing. The point is then simply that each of these modes of seeing-in corresponds to certain types of pictures, and that there are pictures which could be considered "Gombrich paintings," as it were, in that they, allegedly, do not impose their design properties on the viewer's perception, whereas other paintings are more "Wollheimian" in that seeing-in here is clearly doubled with design seeing. In short, such paintings occupy different slots in the matrix below (here slightly simplified), the upper left being Gombrichian, and the bottom right slot being Wollheimian (Table 1).

Here I will concentrate only on the right column (non-illusionistic seeing-in divided from design seeing and non-illusionistic seeing-in doubled with design seeing). The upper right slot plays a key role in Lopes's complexification of the initial standard opposition because it constitutes some sort of articulatory

\footnotetext{
${ }^{9}$ The only type of picture which instantiates this category is allegedly the trompe l'oeil. This is fairly improbable - the category is in my view empty - but here is not the place to discuss this. "Actualism" comprises cases where the design of the picture or of the pictorial/plastic representation at large is what it represents. Lopes's main or rather sole example here is Jasper Johns's target pictures, since seeing the picture is an experience which is indistinguishable from seeing a target (and therefore illusionistic) and doubled with design seeing, because it is in virtue of its design that the picture is a target; the picture could hardly be said to be a representation of a target because it is exactly like targets out there.
} 
Table 1 Types of seeing and corresponding kinds of paintings

\begin{tabular}{l|l|l}
\hline Seeing-in & Illusionistic & Non-illusionistic \\
\hline Divided from design seeing & Trompe l'oeil & Naturalism \\
\hline Doubled with design seeing & "Actualism" & Twofoldedness \\
\hline
\end{tabular}

Adapted from Lopes (2005, p. 40)

domain between Gombrich's illusionism and Wollheim's twofoldness: it comprises paintings that divide seeing-in from design seeing but are not illusionistic as a result. So we are dealing with paintings where the phenomenology of seeing-in is clearly distinguishable from seeing the represented object face to face, but not because the design as design forces itself upon our perception. Lopes calls that category "naturalism," and I believe it covers a wide, not explicitly demarcated range of pictures that are "lifelike" or realistic in that the depicted object is readily recognizable. Examples could be a portrait by Jan van Eyck, a natural scene by John Constable, the annunciation by Antonello da Messina, or some interior by Vilhelm Hammershøi. Now-and here we are back at the question I asked above-if these paintings are not illusionistic, even though seeing-in does not double with design seeing, then seeing-in must double with something else (otherwise we would have the impression of seeing the depicted object face to face, as in trompe l'oeil). Lopes proposes that it is surface seeing:

Naturalistic pictures are not illusionistic, since they always double with surface seeing and so are apprehended as pictures. At the same time, they defeat twofold seeing-in-seeing the depicted scene blocks seeing their designs (Lopes 2005, p. 40).

On the contrary, the kind of pictures dubbed "twofoldness" impose awareness of their design in that the objects we see in them do not in any way resemble the objects we see face to face (ibid.).

The perceptual correlate of the former kind of pictures is what has recently been called "uninflected" seeing-in: the perception of represented objects without awareness of the medium (design properties); whereas the perceptual correlate of the latter type of pictures is called "inflected" seeing-in: perception of objects in pictures accompanied by conscious awareness of their design properties, or perception which is hindered by spontaneous recognitional immersion in the represented scene. ${ }^{10}$

There are apparently good reasons to establish this distinction. First, apparently it captures a genuine ontological and phenomenological difference, i.e. the difference between, on the one hand, pictures with obtrusive designs and pictures with transparent designs and, on the other, the corresponding visual experiences. Second, as Nanay (2010, pp. 185-186) observes, it may serve to unravel an ambiguity in Wollheim's notion of twofoldness, which can either be understood as (1) a visual experience in which we are consciously aware of both the objects represented in

\footnotetext{
${ }^{10}$ This is not the place to develop the distinction between inflected and uninflected perception. Nanay (2010) provides an instructive discussion of this issue.
} 
the surface and the surface (along with the design properties of the painting), or as (2) a visual experience in which both of these are represented, but not necessarily consciously attended to. Inflected seeing-in doubled with design seeing corresponds to the former, while uninflected seeing-in divided from design seeing corresponds to the latter.

However well it addresses the above concerns, this solution is nevertheless infelicitous: it indeed creates new, quite arduous problems. I will mention a couple of them here.

The matrix model and its combinatory logic seem to require that seeing-in divided from design seeing but doubled with surface seeing, on the one hand, and seeing-in doubled with design seeing, on the other, are two different categories and can therefore be easily distinguished. To my knowledge, however, there are no criteria for distinguishing naturalistic paintings from paintings that elicit design seeing; and what is more, to my knowledge no one has ever tried to define standards for establishing this categorial distinction. The present state of affairs thus begs the question: When is seeing-in divided from design seeing and when is it doubled with design seeing? The problem is not simply that there are no criteria for distinguishing between the two-after all, categories can easily exist even if it is impossible to consistently define the sufficient and necessary conditions for belonging to them. What is worse is that it is difficult (to say the least) to point to examples that would instantiate the categories in a clear-cut way.

Take Clark in the above-mentioned Gombrich anecdote. If at some point he felt the urge to figure out how Velázquez had pulled off his stunt, is that not because a specific design property had become obtrusive to him and thus a genuine part of his seeing-in (even though the picture is perfectly naturalistic)? Or the other way around: To Wollheim - for reasons which are proper to his notion of "naturalism"Picasso's Dora Maar is as good an example of naturalism as any, and so are many of Monet's paintings, however obtrusive their design properties may be (Wollheim 1987, pp. 72-75). ${ }^{11}$

We can even consider this from the perspective of prototype theory (Rosch 1978), that is, place good examples of twofold paintings at one end of the continuum, epitomes of naturalistic paintings at the other, and accept intermediary types in-between. It will be difficult to maintain the distinction as long as we do not establish or suggest what pictorial properties elicit design seeing along with seeing-in. Imagine walking through the continuum from cubism, via expres-

\footnotetext{
${ }^{11}$ Wollheim's point in his discussion of naturalism is that the "lifelikeness" or "realism" one associates with naturalism is not a result of the "configurational" aspects of the painting (its surface properties) receding in our perception and leaving the scene to its "recognitional" aspects in order to trigger pure seeing-in. Instead, naturalism is a result of something he, with deliberate vagueness, calls the "reciprocity" of the two aspects of picture seeing. It may of course be considered disappointing that Wollheim assigns more or less ineffable properties to the relation of reciprocity between configurational and recognitional aspects, which trigger a naturalistic effect. Now, this is no less disappointing than the absence of firm criteria on which the distinction between naturalistic and twofold paintings could be based. At least the vagueness is endorsed in his case.
} 
sionism, pointillism, impressionism-all fair examples of paintings which trigger twofold perception - and on to naturalistic paintings such as Caillebotte's Baigneur s'apprêtant à plonger or Ingres's portrait of Princess Albert de Broglie. Now consider the Caillebotte. It is a painting that (according to the intuitive definition proposed by Lopes, and endorsed by Nanay) should be considered a genuine piece of naturalism. But what are we to make of the fact that two of the three bathers are wearing exactly the same swimsuit? Would that not count as a remarkable or significant design property (granted that this coincidence is rather improbable)? And what about the fact that the three bathers occupy the three key stages of the depicted event: one is just about to dive, another is in the water, and the third is just getting out of the water? Is this not a remarkable or compositional design feature? And what about the framing? Is it not a remarkable design feature that the right side of the scene has been cut off? And if not, why not?

In short, each of these features-as well as, for example, the photorealistic presence of Princess Albert de Broglie in Ingres's portrait (cf. Livingstone 2002) is considered to be an authentic design feature (which it obviously is), and so the proposed distinction is shallow. If the features are not considered design properties, then design in paintings rarely has something to do with the tools and techniques painters use to shape their meaning intentions and create specific visual experiences of the scenes they depict. Yet this is exactly the function one should assign to design.

Another reason why Lopes's distinction between surface and design seeing is unsatisfactory is phenomenological in nature and easy to explain. Following a strict definition of surface, surface comprises all the physical accidents on the painted surface, without regard for whether they have a depicting function or not. This is why I have said that surface properties, following this definition, are real parts of our experience of a picture-something has to be there for it to be seen-but they are not genuine features of the aesthetic experience. The orientation of the surface, the contingent lighting conditions in ambient space, the cracks in the pigment, and so on and so forth do affect my perception, but not picture seeing proper. However, if we consider that naturalistic paintings elicit seeing-in doubled with surface seeing, then surface seeing is an essential part or genuine feature of the phenomenology of that experience. If this is true, surface as defined here is not the same thing as Lopes's definition of surface; in fact, it is indistinguishable from Wollheim's definition of it and it is therefore part of twofoldness.

\subsection{Surface as Material Support vs. Surface as a Depicting Plane}

The above issues are relevant in the present context, because addressing them may help us better sort out Wollheim's ambiguous notion of surface, sometimes defined as (1) material support of depiction, at other times as (2) a depicting plane distinguishable from the physical canvas. The confusion I have just pointed to is 
probably due to the fact that, according to Lopes (2005), when seeing-in is doubled with surface seeing, it is doubled with (2), whereas when he defines surface seeing, surface is understood in terms of (1). Here is another of Wollheim's definitions of surface, now as a depicting plane:

The point that I must now clarify is that, in thinking of naturalism as lying in some kind of reciprocity or match between the two aspects of seeing-in, we must be careful not to equate awareness of the marked surface with attention to the brushwork. Attention to the brushwork is just one form that awareness of the marked surface can take, and it is not a form that, for historical reasons, it could have taken before 1500 or so, when the unit mark or stroke came to be thematized. But, long before the stroke became a required object of aesthetic scrutiny, there were plenty of other features of the marked surface that claimed attention: contour, modulation, punch mark, aerial perspective, fineness of detail, as well as, for that matter, smoothness of surface or invisibility of brushwork. (Wollheim 1987, p. 75)

Here surface is not simply canvas, that is, the material support of certain marks; it is (as already mentioned) a transformed support, a pictorial surface endowed with properties that material supports cannot have. Walls or canvases as such cannot be said to have an aerial perspective, fineness of detail, or be characterized by the invisible brushwork; but they can of course constitute the material support for the surface that displays such properties. This is why, still according to Wollheim, seeing naturalistic paintings, even the most naturalistic ones, is just another form of twofold perception.

So here is the distinction, which should be clearly marked within the Wollheimian approach, between seeing things in walls, clouds, or any other form of material support, and seeing things in paintings. In the former case, you recognize an object and you are aware of surface properties that specify the objective support (cloud, wall, frosty pane, etc.); in the latter case, you recognize an object and you co-perceive surface properties that specify the depicting surface (not the material support, of which you are only vaguely aware).

\subsection{Object Awareness}

I will now finally turn to what I referred to above as object awareness. As we have already seen, Lopes (2005) explains the non-illusionistic character of naturalistic pictures in terms of seeing-in doubled with surface seeing. However, according to this account, surface seeing cannot be restricted to naturalistic paintings alone, since no picture seeing is illusionistic in any relevant respect (pace trompe l'oeil). Wollheimian or design obtrusive pictures of course also elicit surface seeing, not simply because their design stands out, but also because we are aware of them as objects.

Thus, Lopes's use of surface seeing is infelicitous in two respects. First, surface seeing comprises elements that are not genuine features of aesthetic perception (seeing-in is doubled with the wrong kind of seeing); and second, this kind of seeing cannot be restricted to one type of picture. However, there is a good reason why 
Lopes resorts to it, and that is the non-illusionistic character of picture seeing, as even the most immersed perceptual experience of a painting is accompanied by the awareness that this is a painting, not a window to some garden or a person seen face to face. So seeing-in must be doubled with something, and if, for the reasons advanced above, surface seeing is a bad candidate, something else must be recruited.

This something is what I call object awareness. It should be understood as passive awareness of the reality status of the thing(s) we are dealing with, not as a specific way of attending to an object. Object awareness is the general horizon within which the visual experience takes place, not some specific way of seeing. Consider, for instance, a museum: before I stand in front of a painting in order to have an appropriate experience of it, I have approached it, identified it as a thing pertaining to a certain category of things, and when I find myself standing in front of it and start attending to it as a specific kind of object (a depicting object), this initial awareness of its nature recedes, it is no longer the focus of my attention (as it was when I oriented my movements toward it). But it does not disappear; it continuously accompanies my visual experience. It is not something that seeing-in is doubled with-i.e. it is not something that informs the content of my visual experience (unlike the perspectival design properties of Piero della Francesca's Annunciation, for instance). Rather, it is something that serves as a general reality anchor for both seeing-in at large and visual experience in general. ${ }^{12}$

This was, then, my simplification of the matrix presented in Lopes (2005). It is a simplification that targets the phenomenology of aesthetic experience and is motivated by two observations. First, there are no criteria for distinguishing pictures that only elicit seeing-in doubled with surface seeing from pictures which also double with design seeing. Second, surface seeing, as it is defined in the case of "naturalistic" paintings, is the perception of a surface which has been designed to be pictorial or expressive and is therefore different only in degree and not in nature from design seeing proper, which is the awareness of the actual design through which something is shaped on the surface or in the picture. It thus makes sense to talk about degrees of twofoldness through all instances, from the most naturalistic to the most design obtrusive ones.

\section{Multiply Depicting Design and Semiotic Design}

Now I would like to proceed with the other sense, namely toward a "complexification" of our notion of design as an object. I intend to unfold this complexification along two lines. First, I will point to a depicting property of design which, in my view, is a distinctive property of pictures, that is to say, not something all pictures instantiate, but something pictures can do and other objects cannot do, or something

\footnotetext{
${ }^{12}$ Object awareness of this sort is of course also a vague form of attention that accompanies even the most immersed reading or movie experiences.
} 
some pictures do and other objects do not. Design in pictures can depict two (or, in rare cases, more) fully consistent objects without the picture becoming ambiguous or bi-stable. Along the second line, I will pose a couple of questions about what counts as design. If I am right to consider the design level of a picture a genuine platform of meaning making, then seeing-in doubled with design seeing occurs every time lines and shapes do not only depict, but also mean something (in virtue of their morphology and qualitative properties and in virtue of the relations between them). This argument hinges, of course, on the possibility of bestowing meaning upon spatial phenomena.

\subsection{Design That Depicts Multiple Objects}

Consider the lithography below (from 11 Configurations) by Jean Arp (Fig. 3). As Arnheim (1954, pp. 234-235) remarks, it is at least amenable to five consistent interpretations (of which the following three will suffice): (a) a small black patch on top of a larger white patch, which in turn rests on a large black patch; (b) a white patch with a hole resting on a large black patch; (c) a large ring-shaped black patch with a small black patch in the middle resting on a white background.

These interpretations are based on different perceptual grouping processes. In the pyramidal (a) interpretation, the white patch is believed to continue under the small black patch, while the large black patch is believed to continue under the white patch. This is a perfectly normal phenomenon; this is indeed the way perception constantly operates in everyday life. What is less normal is that the object also lends itself to interpretations (b) and (c), even though it is based on the very same

Fig. 3 Jean Arp, from 11 Configurations, 1943. (C) VG Bild-Kunst, Bonn 2014

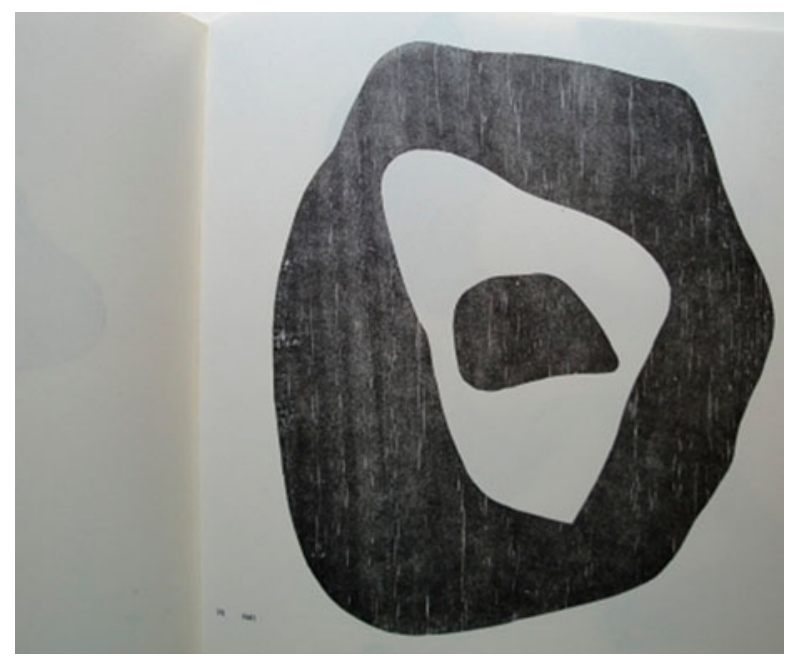


perceptual grouping mechanisms. In everyday perception, our visual brain may, on certain occasions, come up with two conflicting interpretations of an object; but one of them would be wrong. But this is not what we are seeing here. Here all the above interpretations are equally consistent.

So what kind of depicting object is this? It is tempting to consider it a duckrabbit kind of object, in that it is impossible to ultimately determine what it depicts: all the above interpretations are equally possible. However, the duck-rabbit case has been designed to be ambiguous, i.e. to elicit bi-stable perception. This is not the case in Arp, where the picture has been designed to depict several objects without eliciting any bi-stability: the picture can be reconfigured at will as depicting this or that object.

I call this property of pictures "multiply depicting design." It is a pervasive phenomenon in art, richly instantiated and exploitable in countless ways. It is nevertheless a phenomenon that has by and large been neglected, if not simply ignored, in the philosophical discussions and debates on depiction or pictorial representation. ${ }^{13}$ Note that multiply depicting design does not boil down to seeingin doubled with awareness of design (or style or any other expressive property of the depicting surface); it is multiply depicting stricto sensu, and it is so in a manner which may be considered even more spectacular than Arp's configuration. Arp's depicting surface depicts many different objects, but they all appear in an (abstract) represented space. In contradistinction to this, most multiply depicting designs give access to objects represented in different spaces: recognizable objects in painted 3D space (e.g. ships, flowers, buildings, trees, and so on), and abstract shapes in pictorial 2D space. Epitomes of multiply depicting designs are Monet's late paintings, in which lines and colors, on the one hand, give access to, for example, branches and reflections of branches and leaves in the water and in a painted, represented space; but, on the other, can be regrouped in the pictorial, presenting space as abstract vertical green shapes on a blue background (see also Bundgaard 2002, 2004, 2009). Here is an example that (for purely aesthetic reasons) exploits the very same property of depicting surfaces:

In Frank's picture, it is relatively easy to identify the objects appearing in the represented space: a newspaper and magazine stand, a street lamp, a building in the background (however, due to vantage point and framing, it is actually difficult to capture the exact spatial layout of the scene: what is the distance between objects in the foreground and objects in the background? Is there a middle ground-say, the rectangular blocks below and behind the street lamp?). At the same time, a salient property of the picture is that it has been designed to make the visual brain group the represented objects in one, abstract vertical figure appearing as a configuration

\footnotetext{
${ }^{13}$ Arnheim is a remarkable exception. The present argument comes close to his (1954, pp. 127-129) acute double observation: (1) Based on its style, a picture occupies different positions between two extremes, namely the total $2 \mathrm{D}$ flatness of its plane and the full-blown three-dimensionality of the world it represents; (2) pictures can be composed in two ways: both with regards the arrangement of figures in the represented space and with regards the arrangement of shapes on the plane.
} 
Fig. 4 Robert Frank, from The Americans, 1959, picture 62: 23rd Street, NYC

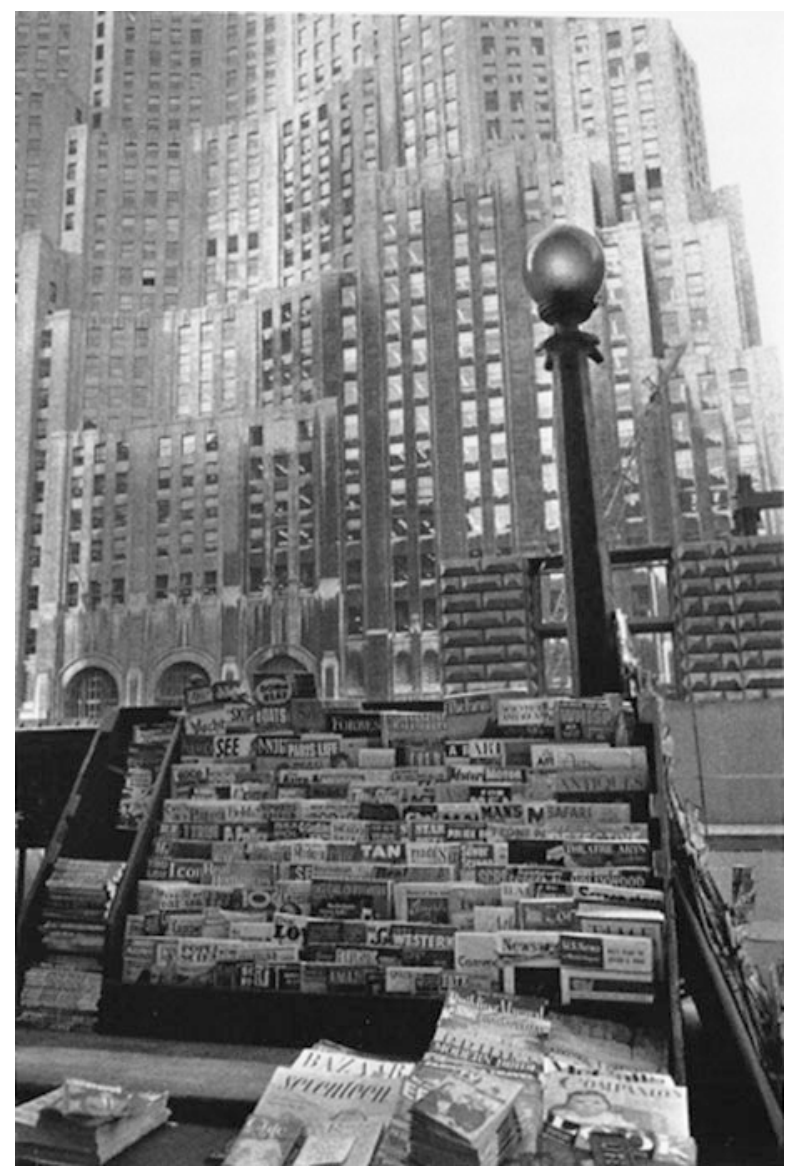

of rectangles on an abstract background. In other words, this picture epitomizes an essential property of a specific kind of depicting object: those which facilitate double seeing-in: a recognitional one, which picks up the represented objects, and a configurational one, which picks up the abstract structure of shapes (Fig. 4).

The depicting elements of such pictures have been designed (or possess a design) to both tap into the grouping automatisms of low-level perception and thereby present pure, organized shapes on a pictorial surface (across categorial differences) and provide the higher order top-down-oriented levels of the visuo-cognitive system with enough cues to allow it to recognize objects and natural sceneries in a represented space. In short, in virtue of certain types of design, marks on a depicting surface can both be configured as pure Gestalts standing out from a background and reconfigured into represented objects in sceneries, landscapes, interiors, and so on. Key to these kinds of design is that each depicted object level is consistent and structured, and that these object levels do not share the same part-whole structure 
(the organization of the shapes as pure Gestalts runs counter to the organization of the represented space and the things in it. They do not share the same contours; what is separated in the representation of, say, a cityscape-buildings, magazine stand-may be fused at the pure Gestalt level). ${ }^{14}$

As I have already mentioned, this design property is rarely commented upon in the literature about depiction and seeing-in. This is probably because depiction has been construed in a narrow sense: as that which enables a visual recognitional experience of a represented object. It is nevertheless interesting, first and foremost because it is a case of double depiction. The homogeneous shape made of rectangular figures we may see in Frank's photograph is depicted in virtue of the design of the photograph. These figures, as well as the homogeneous shape, are not the design. In other words, when I see this kind of abstract shape, I do not see the design as design; I see a well-formed shape in virtue of the design. It is interesting because it does not immediately fit into the categories of seeing-ineven in Lopes's pluralistic matrix - since none of them accommodate this general phenomenon which we could dub "double seeing-in doubled with design seeing," that is, seeing a recognizable object in a picture and seeing a well-formed shape in virtue of the same design, which therefore becomes obtrusive in perception.

Artists often detach the automatisms of perception from their primary and only task in everyday perception, which is to further fast, smooth, and efficient object recognition. They do so not to hinder such recognition or delay it (or whatever our reward system, according to certain scholars, might find exciting; see Ramachandran and Hirstein 1999 for a defense of this claim, and Bundgaard 2014 for a critique of it), but simply to produce double organizations from one design: one for the eye (pure shapes) and one for the mind (recognizable forms).

\subsection{Design as a Platform for Meaning-Making}

I will now turn to the second line of complexification. I would suggest that a definition of design as the configuration of marks on a 2D surface in virtue of which something is depicted seems, at first glance, quite broad. It may, nevertheless, turn out to be too restrictive if we insist on describing design structure strictly as that which is responsible for what we see. Or in other words, I would suggest that design in pictures is also a part of what we understand in a picture, or the different kinds of meaning with which a picture has been bestowed. This is probably far from controversial; it may even seem trivial. It has consequences, however, because if this is true, then twofoldness in Lopes's strict sense of seeing-in doubled with design seeing may be at work when we perceive even very straightforwardly naturalistic paintings.

\footnotetext{
${ }^{14}$ See Bundgaard 2009 for a more detailed discussion of this.
} 
Before I explain why this is so, the following should be made clear. The point we are dealing with here is different from the one I made when discussing the relation between surface seeing and design seeing (from a Wollheimian point of view, against Lopes as it were). From a Wollheimian point of view, picture seeing is twofold in nature, as is the visual experience of a naturalistic painting, of course. What I mean to say now is something else. Even in cases where the design of a painting is not visually obtrusive, seeing-in may be doubled with design seeing in Lopes's strong understanding: those are cases where the design, albeit visually unobtrusive, is semiotically salient, i.e. it enables a visual experience with a certain meaning.

Why is this the case? Simply because phenomena like composition, perspective, vantage point, or contrast are well-known tools for meaning making in art, and because artists arguably resort to them in order to produce certain meaning effects in their works - meaning effects that often depend not solely on the represented forms as such, but on the relation between these forms, their color, the value which their shape or orientation has been attributed locally, viewpoint, and so forth: things that can be read off the surface by (at least trained) viewers. In many cases, the use of such techniques and tools for meaning making is also visually salient (for instance in Piero della Francesca's Annunciation). In certain cases, however, this is less evident.

Let me illustrate what I mean. Consider Constable's The Leaping Horse (Fig. 5).

This might be regarded as belonging to the group of naturalistic paintings in that nothing conspicuous is going on in terms of brushstrokes, color, shape, or viewpoint. However, if we compare it to the studies that preceded it, we can observe a series of

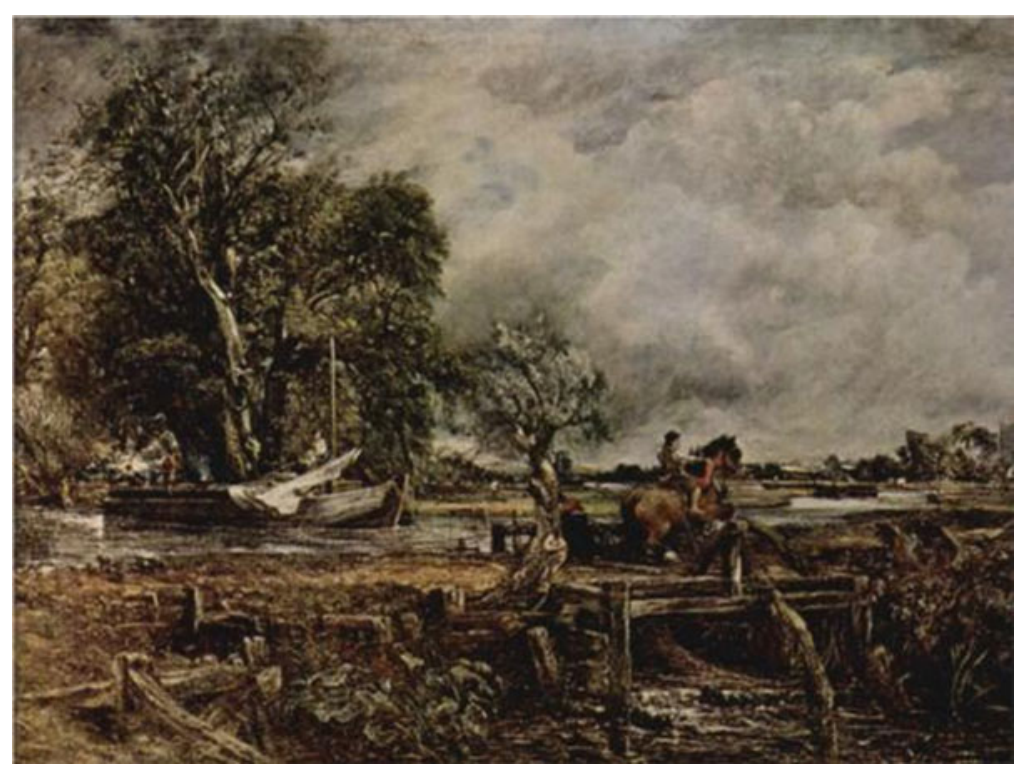

Fig. 5 John Constable, The Leaping Horse, 1825 
remarkable changes - not as regards the depicted objects and the scenery as such, which all remain the same, but as regards their arrangement, their orientation, and their shape or morphology. In these studies, the tree to the left of the leaping horse is placed to the right of it (on the depicting surface, of course); it was bending to the left; there were two boats to the left, both moving, one man was poling, and so on. Whatever the meaning effects of these changes are, we have good reasons to believe that they reflect the artist's intentions. If it is sensible to assimilate arrangement and shape of parts as an essential element of a picture's design, Constable has aimed at doubling seeing-in with seeing a design where the static verticality of the left side of the painting is enhanced as a global contrast to the leaping horse's dynamic horizontality. It is in this sense that the design may be visually unobtrusive, but semiotically salient. In such cases - and to use Lopes's terms - seeing-in is divided from visual design seeing, but doubled with semiotic design seeing. (The above comments on Caillebotte suggest exactly the same thing.)

As suggested, this is a common aspect of paintings - the fact that they articulate semantic values by means of composition or vantage point and perspective. I am not sure, however, that design as a platform for meaning making, that is, as a tool for shaping expressive meaning intentions, is considered just as primary as design construed as a platform for depiction tout court. My contention is that the semiotic function and the depicting function in painting are fused. The former is not simply supervenient on the latter and it is not something that needs to be decoded or inferred from the represented figures: in many cases meaning is right in the morphology of figures, in their resemblance, in their color, in their relative size, in their position on the surface or in the represented space. And in many cases, these phenomena tap into what is meaningful for our visual brain.

If this is so, aesthetic experience is twofold in essence. We see things in pictures, and we see them in a meaningful substrate, on a meaningful surface, that is to say, on an intentionally designed expressive surface.

\section{Conclusion}

The main claim in this article is that a distinction should be made between surface as the material support of a painting and surface as a depicting plane. The visual experience of paintings is twofold in that seeing-in is doubled with co-awareness of the depicting surface, either because its design is visually salient, or because the design is semiotically salient, or both. The transformation of a material support into a depicting surface upon which meaning has been bestowed (or which gives shape to a meaning intention) is an essential (albeit not exclusive) property of paintings. Correlatively, the perception of paintings is characterized by being an encounter with visual meaning at large articulated in shapes, colors, strokes, and lines. An important task still remains in determining what is meant by meaning in pictorial art, i.e. to chart its different types of manifestation. This, however, was not the aim of the present chapter. 
Open Access This chapter is distributed under the terms of the Creative Commons Attribution Noncommercial License, which permits any noncommercial use, distribution, and reproduction in any medium, provided the original author(s) and source are credited.

\section{References}

Arnheim, Rudolf. 1954. Art and visual perception. Berkeley/Los Angeles/London: University of California Press.

Bundgaard, Peer F. 2002. Presentation and representation in art-Ontic and aesthetic constraints on aesthetic experience. Visio 7(1-2): 187-204.

Bundgaard, Peer F. 2004. Kunst-semiotiske beskrivelser af astetisk betydning og oplevelse. Copenhagen: Haase og Søn.

Bundgaard, Peer F. 2009. Towards a cognitive semiotics of the visual artwork-Elements of a grammar of aesthetic intuition. Cognitive Semiotics 5: 42-65.

Bundgaard, Peer F. 2011. The grammar of aesthetic intuition-On Ernst Cassirer's concept of symbolic form in the visual arts. Synthese 179: 43-57.

Bundgaard, Peer F. 2014. Feeling, meaning, and intentionality-A critical assessment of the neuroaesthetics of beauty. Phenomenology and the Cogntive Sciences. doi:10.1007/s11097014-9351-5.

Gombrich, Ernst. 1960. Art and illusion-A study in the psychology of pictorial representation. Oxford: Phaidon Press.

Husserl, Edmund. 1980. Husserliana XIII, Phantasie, Bildbewusstsein, Erinnerung. Zur Phänomenologie der anschaulichen Veregenwärtigungen. The Hague: Nijhoff.

Hyman, John. 2003. Subjectivism in the theory of pictorial art. The Monist 86(4): 676-701.

Hyman, John. 2006. The objective eye. Chicago: The University of Chicago Press.

Livingstone, Margaret. 2002. Vision and art: The biology of seeing. New York: Abrams.

Lopes, Dominic. 2005. Sight and sensibility_Evaluating pictures. Oxford: Oxford University Press.

Nanay, Bence. 2010. Inflected and uninflected experience of pictures. In Philosophical perspectives on depiction, ed. Catharine Abell and Katerina Bantinaki, 181-207. Oxford: Oxford University Press.

Petitot, Jean. 2009a. Non-generic viewpoints as a method of composition in renaissance paintings. Cognitive Semiotics 5: 7-41.

Petitot, Jean. 2009b. Morphology and structural aesthetics: From Goethe to Lévi-Strauss. In The Cambridge companion to Lévi-Strauss, ed. Boris Wiseman, 275-295. Cambridge: Cambridge University Press.

Ramachandran, Vilayanur S., and William Hirstein. 1999. The science of art-A neurological theory of aesthetic experience. Journal of Consciousness Studies 6(6-7): 15-51.

Rosch, Eleanor. 1978. Principles of categorization. In Cognition and categorization, ed. Eleanor Rosch and Barbara B. Lloyd, 27-48. Hillsdale: Lawrence Erlbaum.

Wollheim, Richard. 1987. Painting as an art. Princeton: Princeton University Press. 